\title{
Ataxia of Charlevoix-Saguenay: MR and Clinical Results in Lower-Limb Musculature
}

\author{
José Gazulla, Esteban Mayayo-Sinués, Isabel Benavente, Pedro J. Modrego, \\ José Berciano
}

\begin{abstract}
Objective: Peripheral neuropathy is a cardinal manifestation of the autosomal recessive spastic ataxia of CharlevoixSaguenay (ARSACS), although its type of neuromuscular involvement has not been definitely established, and magnetic resonance imaging (MRI) plays an important role in the assessment of muscle and nerve diseases. The objective of this work has been to define the patterns of muscle weakness and of abnormal muscular MRI in ARSACS. Patients and Methods: Five patients with a molecular diagnosis of ARSACS, aged 39 to 59 years, whose electrophysiological findings were consistent with an axonal neuropathy of distal distribution superimposed on a developmental defect of myelinization, underwent neurological and MRI lower-limb examinations. Conventional FSE T1-weighted and STIR sequences were performed, looking for fatty infiltration and oedema in the musculature of the thighs, legs and feet, together with their distribution along the longitudinal axis of the muscle bellies. Results: On clinical examination, paralysis was apparent in foot muscles; moderate weakness, in leg musculature; and normal strength, in thigh muscles. MRI demonstrated massive fat deposition in the foot muscles and medial gastrocnemii in every case, distal fat infiltration and oedema in every leg muscle group, and preservation of thigh muscles, albeit with diffuse minimal non-specific fat infiltration. An inverse correlation between strength and degree of fat infiltration in lower-limb muscles became apparent. Conclusion: The preponderance of weakness and MRI abnormalities in distal muscle groups was concordant with the presence of a length-dependent axonopathy, as described in ARSACS.
\end{abstract}

RÉSUMÉ: Ataxie de Charlevoix-Saguenay : IRM et observations cliniques au niveau de la musculature des membres inférieurs. Objectif : La neuropathie périphérique est une manifestation cardinale de l'ataxie spastique de Charlevoix-Saguenay (ARSACS), une maladie récessive autosomique. Cependant, le type d'atteinte neuromusculaire n'a pas été établi avec certitude et l'imagerie par résonance magnétique (IRM) joue un rôle important dans l'évaluation des maladies des muscles et des nerfs. Le but de cette étude était de définir les caractéristiques de la faiblesse musculaire et des anomalies musculaires observées à l'IRM dans l'ARSACS. Méthode : Cinq patients atteints d'ARSACS, dont l'âge variait de 39 à 59 ans et dont le diagnostic avait été confirmé par la biologie moléculaire et chez qui les constatations électrophysiologiques étaient compatibles avec une neuropathie axonale à distribution distale superposée à un défaut du développement de la myélinisation, ont subi un examen neurologique et une IRM des membres inférieurs. Nous avons recherché sur les séquences conventionnelles FSE en pondération T1 et STIR une infiltration graisseuse et un œdème dans la musculature des cuisses, des jambes et des pieds ainsi que la distribution le long de l'axe longitudinal du ventre des muscles. Résultats : À l'examen clinique, la paralysie était évidente au niveau des muscles du pied ainsi qu'une faiblesse modérée de la musculature de la jambe et une force normale au niveau des muscles de la cuisse. L'IRM a montré des dépôts adipeux importants dans les muscles du pied et la partie moyenne des gastrocnémiens chez tous les patients, une infiltration adipeuse distale et de l'œdème dans tous les groupes musculaires des jambes ainsi qu'une préservation des muscles de la cuisse avec cependant une infiltration graisseuse minimale et diffuse, mais non spécifique. Une corrélation négative entre la force et le degré d'infiltration graisseuse dans les muscles des membres inférieurs a été mise en évidence. Conclusion : La prépondérance de la faiblesse et les anomalies à l'IRM au niveau des groupes musculaires distaux concordaient avec la présence d'une axonopathie qui était fonction de la longueur de l'axone, tel que décrit dans l'ARSACS.

Can J Neurol Sci. 2014; 41: 37-41

\section{BACKGROUND AND OBJECTIVES}

The autosomal recessive spastic ataxia of CharlevoixSaguenay (ARSACS) is a disease caused by mutations in the SACS gene, located on chromosome $13 \mathrm{q} 12.12^{1}$. Believed at first to be restricted to Canada, ARSACS has been diagnosed in various countries since, and the two initial founder mutations identified in the province of Quebec have increased to more than seventy, coming from all around the world. In spite of this, the neuromuscular manifestations in ARSACS are in need of precise clinical and paraclinical characterization.

Magnetic resonance imaging (MRI) has an important role in the detection and characterization of pathological conditions of skeletal muscle, which may bring about changes in muscle signal intensity. Moreover, MRI studies may be of help in identifying specific patterns of muscle involvement in

\footnotetext{
From the Department of Neurology (JG, PJM), Department of Radiology (EMS), Hospital Universitario Miguel Servet, Zaragoza; Department of Clinical

Neurophysiology (IB), Hospital San Jorge, Huesca; Department of Neurology (JB),

University Hospital Marqués de Valdecilla and Centro de Investigación Biomédica en

Red de Enfermedades Neurodegenerativas (CIBERNED), Santander, Spain.

Received June 4, 2013. Final Revisions Submitted July 30, 2013.

Correspondence to: José Gazulla, Luis Vives 6, esc dcha, $7^{\circ} \mathrm{B}, 50006$ Zaragoza, Spain.Email address: josegazulla@wanadoo.es.
} 
genetically distinct entities, such as Charcot-Marie-Tooth disease $(\mathrm{CMT})^{2-6}$ and facioscapulohumeral muscular dystrophy ${ }^{7}$, and also in acquired disorders, such as muscle trauma, compartmental syndromes and acute motor axonal neuropathy ${ }^{8,9}$.

Magnetic resonance imaging studies of striated muscle in ARSACS have not been published to date, as far as these authors are aware. Thus, the aim of this article was to describe the MRI findings in lower-limb musculature in a group of five patients with this disease, and to try to correlate the findings with the neuromuscular manifestations found.

\section{Patients And Methods}

Five previously reported patients with a molecular diagnosis of $\mathrm{ARSACS}^{10}$, aged 39 to 59 years, underwent general, neurological and MRI examinations; patients 3 and 4 were siblings, and patient 5 was born to consanguineous parents. Patient 1 was hemizygous for c.13405G>C/p.A4469P, which replaces alanine 4469 for proline in the HEPN domain, and the other allele harboured a large genomic deletion that encompassed SACS. Patient 2 harboured a c.1894C $>$ T substitution (p.R632W), and a c.12973C > T variant (p.R4325X), which predicts premature protein truncation. Patients 3 and 4 were siblings and harboured the nonsense mutation c.832C $>$ T/p.Q278X in compound heterozygosity with c.9670C $>$ T/p.R3224X; both variants predict premature sacsin truncation, and patient 5, born to consanguineous parents, demonstrated the homozygous mutation c.3198T>A/p.C1066X, which predicts early protein truncation.

Disease duration ranged from 29 to 57 years. Every patient underwent a complete neurological examination, in which strength of the lower-limb muscles was tested manually and graded from 0 (no contraction) to 5 (normal power), according to the scale of the Medical Research Council (MRC); grade 3 indicated active movement against gravity; grade 3.5, movement against gravity and slight resistance; grade 4, movement against moderate resistance; and grade 4.5, movement against strong resistance ${ }^{11}$

Every patient underwent MRI of the lower-limb musculature, performed on a Signa Excite 1.5 T scanner (General Electric Healthcare, Milwaukee, Wisconsin, USA), in which thigh, leg and foot muscles were examined using T1-weighted Fast SpinEcho (FSE, TR/TE, 500-700/9-11 ms) and T2-weighted Short Time Inversion Recovery (STIR, TR/TE/TI, 5300-8500 ms/4050/150 ms) sequences; axial and coronal T1-weighted FSE and STIR acquisitions were obtained of the thighs and legs, with the same sequences in the axial plane for the feet. Image parameters in the thighs were as follows: field of view (FOV), 38-42 cm; slice thickness, 4-4.5/4.5-6 mm (coronal/axial), and slice gap, 1.5-2/3-5 mm (coronal/axial). In the legs, FOV was 36-38/28-32 $\mathrm{cm}$ (coronal/axial); slice thickness 4-4.5 mm, and slice gap, 1$1.5 / 2-3.5 \mathrm{~mm}$ (coronal/axial). In the feet, FOV was $21-23 \mathrm{~cm}$, slice thickness 4-4.5 mm, and slice gap, $1 \mathrm{~mm}$. Two signal averages and a matrix size of 256x192 pixels were used in every sequence. The examinations were done with the patient in the supine position, without intravenous contrast agents.

Alterations in muscle signal intensity were systematically looked for. Increases in $\mathrm{T} 1$ signal intensity caused by fat infiltration were estimated in a semiquantitative manner, according to the classification by Goutallier et $a l^{12}$, adapted to MRI specifications in the axial and coronal planes ${ }^{4,12}$ : 0 , no evidence of fatty infiltration; 1 , some fatty streaks; 2 , fat evident, but less extensive than muscle; 3 , fat equal to muscle; 4 , fat more extensive than muscle. The distribution of fat along the muscle belly was also analyzed, considering there was a positive gradient when the fat content increased distally through the long axis of the muscle, and absence of gradient, when the hyperintense signal was similar along the muscle.

In addition, we searched for increased signal intensity on STIR images, correspondent to oedema caused by subacute denervation; We also looked at signal intensity distribution along
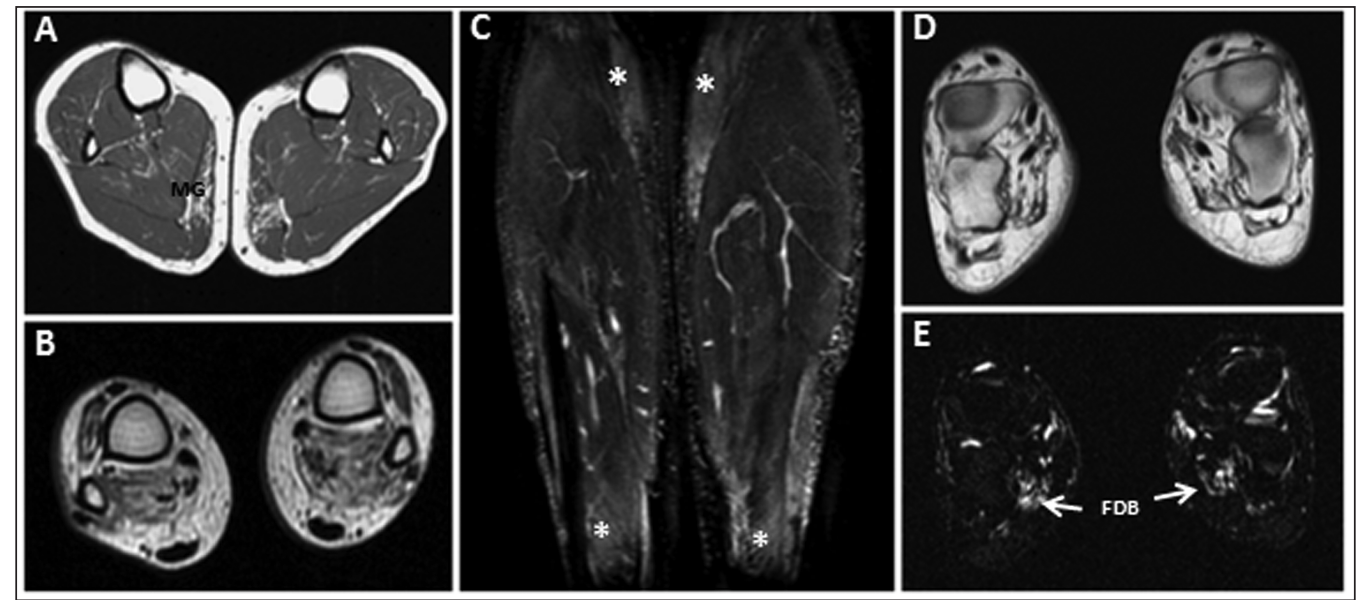

Figure 1: Axial T1-weighted MR of the middle (A) and distal (B) thirds of the legs, showing prominent distal fat infiltration, the fat deposit being limited to the gastrocnemius medialis in the middle third of the leg. Coronal STIR T2-weighted MR of the legs, showing distal oedema in the soleus $(*)$, deep flexor and peroneal muscles, together with diffuse oedema in the gastrocnemius medialis muscles $(C)$. Axial T1-weighted (D) and STIR (E) MR sequences show atrophy and severe fat infiltration in the plantar muscle groups, these being massive in the dorsal foot muscles; oedema is seen in the flexor digitorum brevis (FDB). 
the muscle belly. We described signal intensity as diffuse when it affected most of the length of a muscle, or distal, if it was present in the distal third only.

The peronei longus and brevis, and the extensor hallucis longus and extensor digitorum longus, were assessed as single muscles respectively, due to difficulty in individualizing their muscle bellies, in addition to the tibialis anterior, tibialis posterior, flexor hallucis longus, flexor digitorum longus, gastrocnemius medialis, gastrocnemius lateralis and soleus; thus, nine muscle units were evaluated in each leg, bringing the total number of leg muscles assessed by MRI to 90 in the study population.

The patients gave informed consent for the realization of the study, which was in accordance with the Hospital Universitario Miguel Servet Ethics Committee.

\section{RESULTS}

\section{Clinical Findings}

On clinical inspection, a straight spine, forefoot pes cavus and hammertoes were observed; severe spasticity in the hips and knees, distal loss of vibration sense in the upper and lower limbs and extensor plantar responses were also found in every patient. Only patient 2 retained independent gait, the others became wheelchair-bound at ages between 39 and 44 years; dysmetria, dysarthria and nystagmus were also present in every case.

On examination of the motor system, atrophy of the foot and hand musculature was noticed in each participant. Muscle power was normal in the hip and thigh muscles while the leg muscles evaluated (tibialis anterior, extensor hallucis longus, extensor digitorum longus, peroneal group, tibialis posterior and gastrocnemius - a total of 60 muscle groups in the study population) exhibited power MRC grade $4 / 5$ in 38 instances $(62 \%) ; 4.5 / 5$ in $14(31.4 \%)$; and $3.5 / 5$ and normal power, in 2 (3.3\%) each one. On testing the foot muscles, no contraction was felt at the extensor digitorum brevis (EDB) or plantar muscles in any patient, none being able to separate or approximate the toes, or cup the soles of the feet.

\section{MRI findings}

The MRI abnormalities were globally symmetric, although subtle differences in lesional degree were found in some muscle groups. With the exception of quadriceps and adductors, the thigh muscles showed diffuse minimal fatty infiltration. In addition, no gradient of fat infiltration was found in any muscles.

The legs exhibited fatty infiltration grade $1(78.1 \%)$ or 2 $(13.2 \%)$ in most muscle groups. The gastrocnemius medialis exhibited the most severe fatty deposition (grade 2 or 3), while the gastrocnemius lateralis was the least involved in every case (Figures 1, 2). Imaging findings of the leg musculature are summarized in the Table.

A positive gradient of fat infiltration was found in 33 of 90 leg muscles (36.6\%), with no gradient manifest in those remaining. Oedema was present in $81.1 \%$ of instances, which was distal in $37.4 \%$, and diffuse in $43.7 \%$.

In the feet, complete substitution of muscle tissue for fat was seen in the interossei and lumbricals (Figure 2). Fat deposition grade 4 was found in plantar and dorsal foot muscles, except for the medial plantar muscle groups, which showed fat infiltration grade 2 to 4 . No gradient of fat accumulation was observed in the feet. Oedema was observed in muscles without massive fat infiltration, especially in EDB. In addition, hammertoes were seen in every patient (Figure 2).

\section{Discussion}

The issue of neuromuscular participation in ARSACS has not been definitely established. It has been claimed to be a myelinopathy ${ }^{13}$, an axonopathy ${ }^{14,15}$, or a disease bearing similarity with the intermediate forms of $\mathrm{CMT}^{16,17}$.
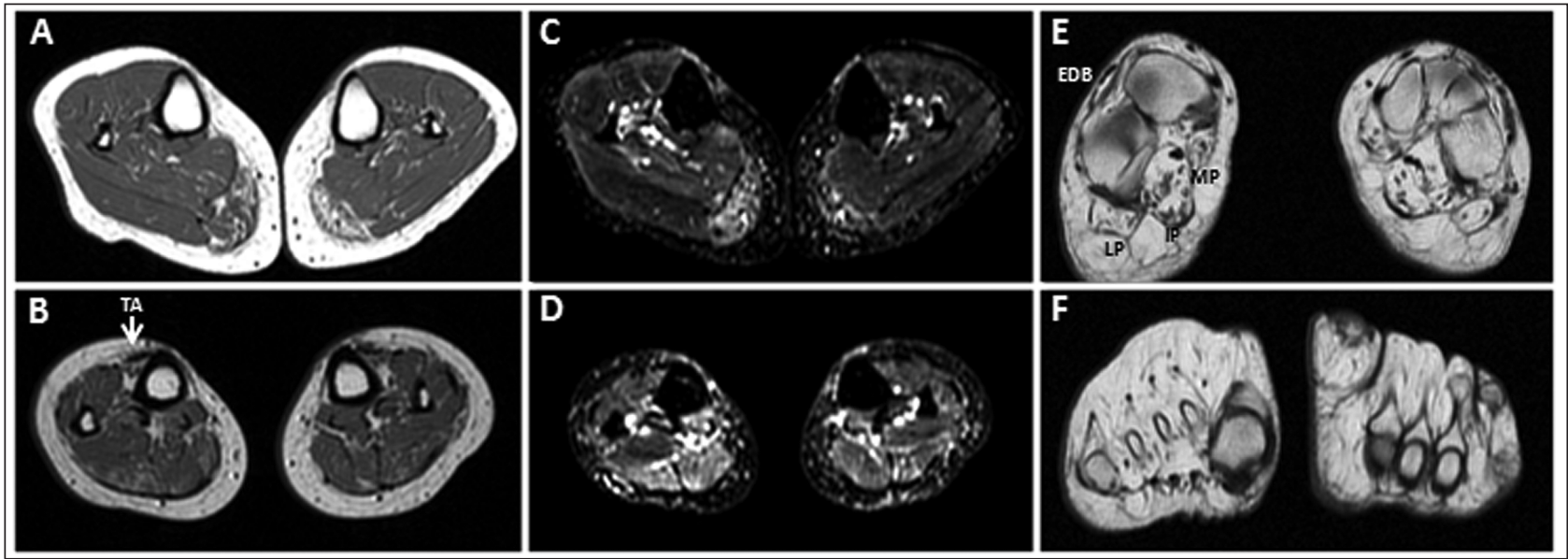

Figure 2: Axial T1-weighted MR of the middle (A) and distal (B) thirds of the legs, with severe fat depositon limited to the gastrocnemius medialis muscles; positive fat infiltration gradient in the tibialis anterior muscles is also evident. STIR axial sequences of the middle (C) and distal (D) thirds of the legs show diffuse oedema in the gastrocnemius medialis, and distal oedema in the soleus muscles. Axial T1-weighted MRI of the middle $(E)$ and distal $(F)$ thirds of the feet, showing complete fat substitution in the interossei and lumbricals (*), extensive fat infiltration in the medial $(M P)$, intermediate $(I P)$ and lateral $(L P)$ plantar muscle groups, and in the extensor digitorum brevis (EDB). Hammertoes are clearly seen in both feet $(F)$. 
Table: MRI findings in leg muscles

\begin{tabular}{|c|c|c|c|c|c|c|c|c|c|c|c|c|c|c|c|c|c|c|c|c|}
\hline & \multicolumn{4}{|c|}{$\begin{array}{l}\text { Patient } 1 \\
\text { Age } 59, \mathrm{~F} \\
\text { Wheelchair }\end{array}$} & \multicolumn{4}{|c|}{$\begin{array}{c}\text { Patient } \mathbf{2} \\
\text { Age 42, F } \\
\text { Walks unaided } \\
\end{array}$} & \multicolumn{4}{|c|}{$\begin{array}{c}\text { Patient } 3 \\
\text { Age 42, F } \\
\text { Wheelchair } \\
\end{array}$} & \multicolumn{4}{|c|}{$\begin{array}{c}\text { Patient } 4 \\
\text { Age 39, M } \\
\text { Wheelchair } \\
\end{array}$} & \multicolumn{4}{|c|}{$\begin{array}{c}\text { Patient } 5 \\
\text { Age 50, F } \\
\text { Wheelchair }\end{array}$} \\
\hline & Rigl & & Lef & & Righ & & Lef & & Righ & & Let & & Righ & & Lef & & Righ & & Lef & \\
\hline & FI/Gr & $\mathbf{E}$ & $\mathrm{FI} / \mathrm{Gr}$ & $\mathbf{E}$ & FI/Gr & $E$ & $\mathrm{FI} / \mathrm{Gr}$ & $E$ & $\mathrm{FI} / \mathrm{Gr}$ & \begin{tabular}{|l|l|}
$\mathbf{E}$ & \\
\end{tabular} & FI/Gr & $\mathbf{E}$ & $\mathrm{FI} / \mathrm{Gr}$ & $\mathbf{E}$ & $\mathrm{FI} / \mathrm{Gr}$ & $\mathbf{E}$ & $\mathrm{FI} / \mathrm{Gr}$ & $\mathbf{E}$ & $\mathrm{FI} / \mathbf{G r}$ & $\bar{E}$ \\
\hline TA & $1 /-$ & - & $1 /-$ & DS & $1 /-$ & DF & $1 /-$ & DF & $1 /+$ & DS & $1 /+$ & DS & $1 /+$ & DF & $1 /+$ & DS & $1 /-$ & DF & $1 /-$ & $\overline{D F}$ \\
\hline $\begin{array}{c}\text { Ext } \\
\text { L }\end{array}$ & $1 /-$ & - & $2 /-$ & $\mathrm{D}$ & $1 /-$ & DF & $1 /-$ & $\mathrm{F}$ & $1 /-$ & DS & $1 /-$ & $\mathrm{DS}$ & + & - & $1 /+$ & $\mathrm{S}$ & $1 /-$ & $\mathrm{DF}$ & $2 /-$ & DF \\
\hline Per & $1 /-$ & - & $2 /-$ & DS & $17-$ & DF & /- & $\mathrm{F}$ & /+ & DS & $1 /+$ & S3 & $1 /+$ & DS & $1 /+$ & 3 & 1/- & DF & $2 /-$ & DF \\
\hline TP & $1 /-$ & DF & $1 /-$ & DF & $1 /-$ & DF & $1 /-$ & DF & $1 /+$ & DF & $1 /+$ & DS & $1 /+$ & DS & $1 /+$ & DS & $1 /-$ & - & $1 /-$ & - \\
\hline HL & $1 /-$ & DF & $1 /-$ & DF & $1 /-$ & - & $1 /-$ & - & $1 /+$ & DS & $1 /+$ & DS & $1 /+$ & DS & $1 /+$ & DS & $1 /-$ & - & $1 /-$ & - \\
\hline$\overline{\mathrm{DL}}$ & $1 /-$ & I & $1 /$ & $\mathrm{DF}$ & $1 /-$ & - & $1 /-$ & - & $1 /$ & DS & $1 /+$ & DS & $1 /+$ & DS & $1 /+$ & S & 1 & - & $1-$ & - \\
\hline Sol & $2 /+$ & DF & $2 /+$ & DF & $1 /-$ & DS & $1 /-$ & DS & $1 /+$ & DS & $1 /+$ & $\mathrm{DS}$ & $1 /+$ & DS & $1 /+$ & DS & $1 /-$ & DS & $1 /-$ & DS \\
\hline $\bar{M}$ & $2 /+$ & DF & $3 /+$ & $\mathrm{DF}$ & $3 /-$ & - & $3 /-$ & - & $2 /+$ & $\mathrm{DF}$ & $3 /-$ & DF & $2 /+$ & DF & $2 /+$ & DF & $3 /-$ & DF & $2 /-$ & $\overline{D F}$ \\
\hline $\mathrm{L}$ & $1 /-$ & DF & $1 /-$ & DF & $2 /-$ & DF & $1 /-$ & DF & $1 /-$ & DS & $1 /-$ & DS & $0 /-$ & DF & $0 /-$ & DF & $1 /-$ & DF & $1 /-$ & DF \\
\hline
\end{tabular}

DS, distal oedema; DF, diffuse oedema; FI: fat infiltration; Gr: gradient of fat infiltration (+, positive; -, absent) E: oedema; Ext L: long extensor muscles (extensor hallucis longus and extensor digitorum longus); F: female; FDL: flexor digitorum longus; FHL: flexor hallucis longus; Per: peroneal muscles (peroneus longus and brevis); TA: tibialis anterior; TP: tibialis posterior; Sol: soleus; GM: medial gastrocnemius medialis; GL: gastrocnemius lateralis; M: male.

The electroneurographic findings in the present group, detailed elsewhere ${ }^{10}$, disclosed abnormalities of conduction that fell into the demyelinating range. In addition, distal motor latencies were prolonged and minimal $\mathrm{F}$ wave latencies increased, while electromyographic signs of chronic denervation were found in distal muscles of the limbs, although not so in proximal ones. These electrophysiological findings were consistent with a myelinopathy, although signs of distal axonal involvement were also present. It is known that Schwann cells exert influence on axonal properties, and that changes induced by abnormal myelin may cause secondary axonal degeneration ${ }^{17,18}$

The present results are in line with others reported previously, which proposed that the neuropathy in ARSACS was caused by a developmental defect of myelination, on which a degenerative process of peripheral axons was superimposed ${ }^{13}$. This situation is similar to that described in demyelinating CMT due to duplication of the PMP22 gene (CMT-1A), in which progressive distal muscle weakness is caused by a slowly evolving lengthdependent degeneration of the motor axons ${ }^{19-21}$.

Therefore, MRI should detect alterations of skeletal muscle in ARSACS, in the same manner as it does in CMT and other diseases that lead to chronic muscle denervation, which manifest as fatty infiltration and muscle atrophy ${ }^{22-25}$. When subacute muscle denervation occurs in the disease process, it is visualized as oedema with high signal intensity images on T2-weighted, STIR and diffusion-weighted MR sequences, which are related to fluid shift into the extracellular space $22-24$; transformation of muscle oedema into fat deposits has been documented by successive MRI surveys in a patient with CMT-1A, implying that subacute nerve lesions may evolve into chronic ones ${ }^{5}$.
The highest degree of muscular degeneration in this series corresponded to the most distal anatomical locations; consequently, the most severely affected foot muscles were the interossei and lumbricals, which showed complete fatty substitution of muscle on MRI, probably as a result of a concluded denervation process occurring there. In contrast, more proximal plantar muscles and EDB displayed intense, though incomplete, fat infiltration (grade 4 of Goutellier), and oedema in the remaining normal tissue.

In good correlation with the massive degree of fat infiltration demonstrated by the imaging studies, no voluntary contraction could be appreciated in any foot muscle on clinical examination; besides, hammertoes were found in every instance, a phenomenon propitiated by weakness of the lumbrical muscles $^{3,5}$.

Moderate fatty infiltration of the leg was noted in every muscular compartment. Such fatty change was maximal (up to grade 3 ) in the gastrocnemius medialis, a phenomenon similar to that seen in CMT-1 $\mathrm{A}^{3}$. Moderate weakness, ranging from MRC grades 3.5 to 4.5 , was present in $96.7 \%$ of leg muscles, corresponding to the partial fatty infiltration detected in the muscles.

A positive gradient of fat infiltration was found in $36.6 \%$ of leg muscles, and distal oedema, in $39.9 \%$. Subacute muscle denervation appears as oedema on $\mathrm{MRI}^{3,22-24}$, and its distal location, together with a positive gradient of fat infiltration in the leg muscles, probably reflects disease activity at the longest nerve branches of the legs.

However, in a chronic disorder such as ARSACS, with very slow clinical deterioration over the years, the presence of oedema might become difficult to explain. Stepwise progression, noted in some CMT-1A patients, was associated with oedema on 
MRI, and caused by acute inflammation superimposed on the hereditary neuropathy ${ }^{26}$, although none of our patients experienced that type of clinical course. Consequently, it might be hypothesized that subclinical nerve inflammation could be an active pathogenic mechanism in ARSACS, and that oedema detected by MRI could constitute an indicator of disease activity, although the possibility that it precedes fatty infiltration in this disease will have to be elucidated in future studies.

Muscle injury was very mild in the thighs, as minimal and diffuse fat infiltration without a longitudinal gradient could be related to lack of muscle use. The preservation of thigh musculature on MRI correlates well with its observed normal power, especially in hip adductor and knee extensor groups, which show increased muscle tone in ARSACS ${ }^{10}$.

\section{CONCLUSION}

Our investigation on five ARSACS patients corroborates that peripheral neuropathy is an integral part of the clinical picture, with good correlation between clinical and lower-limb MRI muscle findings. Our data suggest, in accordance with previously reported electrophysiological data ${ }^{10}$, that this is a lengthdependent axonal degeneration, as distal loss of muscle tissue on MRI, and foot and leg weakness on clinical examination, were present in this series. In addition to distally accentuated muscle fat atrophy, the presence of hyperintense distal muscle signals on STIR sequences points to coexistent oedema (characteristic of subacute denervation), although the pathogenic role of this finding is in need of further studies in ARSACS.

\section{REFERENCES}

1. Bouchard JP, Richter A, Mathieu J, et al. Autosomal recessive ataxia of Charlevoix-Saguenay. Neuromusc Dis. 1998;8:100-2.

2. Berciano J, Gallardo E, García A, Infante J, Mateo I, Combarros O. Charcot-Marie-Tooth disease type 1A duplication with severe paresis of the proximal lower limb muscles: a long-term followup study. J Neurol Neurosurg Psychiatry. 2006;77:1169-76.

3. Gallardo E, García A, Combarros O, Berciano J. Charcot-MarieTooth disease type 1A duplication: spectrum of clinical and magnetic resonance imaging features in leg and foot muscles. Brain. 2006;129:426-37.

4. Gallardo E, Claeys KG, Nelis E, et al. Magnetic resonance imaging findings of leg musculature in Charcot-Marie-Tooth disease type 2 due to dynamin 2 mutation. J Neurol. 2008;255:986-92.

5. Berciano J, Gallardo E, García A, Ramón C, Infante J, Combarros O. Clinical progression in Charcot-Marie-Tooth disease type 1A duplication: clinico-electrophysiological and MRI longitudinal study of a family. J Neurol. 2010;257:1633-41.

6. Gallardo E, García A, Ramón C, et al. Charcot-Marie-Tooth disease type 2J with MPZ Thr124Met mutation: clinicoelectrophysiological and MRI study of a family. J Neurol. 2009; 256:2061-71.

7. Kan HE, Scheenen TW, Wohlgemuth M, et al. Quantitative MR imaging of individual muscle involvement in facioscapulohumeral muscular dystrophy. Neuromuscul Disord. 2009; $19: 357-62$.
8. Costa AF, Di Primio GA, Schweitzer ME. Magnetic resonance imaging of muscle disease: a pattern-based approach. Muscle Nerve. 2012;46:465-81.

9. Berciano J, Gallardo E, Fernández-Torre JL, González-Quintanilla $\mathrm{V}$, Infante J. Magnetic resonance imaging of lower limb musculature in acute motor axonal neuropathy. J Neurol. 2012; 259:1111-16.

10. Gazulla J, Benavente I, Vela AC, et al. New findings in the ataxia of Charlevoix-Saguenay. J Neurol. 2012;259:869-78.

11. Medical Research Council. Aids to the examination of the peripheral nervous system. London: Her Majesty's Stationery Office; 1976.

12. Goutallier D, Postel JM, Bernageau J, Lavau L, Voisin MC. Fatty muscle degeneration in cuff ruptures. Pre- and postoperative evaluation by CT scan. Clin Orthop Relat Res. 1994;304:78-83.

13. Peyronnard JM, Charron L, Barbeau A. The neuropathy of Charlevoix-Saguenay ataxia: an electrophysiological and pathological study. Can J Neurol Sci. 1979;6:199-203.

14. Criscuolo C, Banfi S, Orio M, et al. A novel mutation in SACS gene in a family from southern Italy. Neurology. 2004;62:100-2.

15. García A, Criscuolo C, De Michele G, Berciano J. Neurophysiological study in a Spanish family with recessive spastic ataxia of Charlevoix-Saguenay. Muscle Nerve. 2008;37: 107-10.

16. Berciano J, García A, Infante J. Peripheral nerve involvement in hereditary cerebellar and multisystem degenerative disorders. In: Said G, Krarup C, editors. Handbook of Clinical Neurology. Peripheral Nerve Disorders. Amsterdam: Elsevier Science; 2013;115:907-32.

17. Hattori N, Yamamoto M, Yoshihara T, et al. Demyelinating and axonal features of Charcot-Marie-Tooth disease with mutations of myelin-related proteins (PMP22, MPZ and Cx32): a clinicopathological study of 205 Japanese patients. Brain. 2003; 126:134-51.

18. Martini R. The effect of myelinating Schwann cells on axons. Muscle Nerve. 2001;24:456-66.

19. García A, Combarros O, Calleja J, Berciano J. Charcot-Marie-Tooth disease type $1 \mathrm{~A}$ with $17 \mathrm{p}$ duplication in early infancy and childhood. A longitudinal clinical and electrophysiological study. Neurology. 1998;50:1061-7.

20. Krajewski KM, Lewis RA, Fuerst DR, et al. Neuronal dysfunction and axonal degeneration in Charcot-Marie-Tooth disease type 1A. Brain. 2000;123:1516-27.

21. Stillwell G, Kilcoyne RF, Sherman JL. Patterns of muscle atrophy in the lower limbs in patients with Charcot-Marie-Tooth disease as measured by magnetic resonance imaging. J Foot Ankle Surg. 1995:34:583-6.

22. May DA, Disler DG, Jones EA, Balkissoon AA, Manaster BJ. Abnormal signal intensity in skeletal muscle at MR imaging: patterns, pearls and pitfalls. Radiographics. 2000;20:S295-313.

23. Kamath S, Venkatanarasimha N, Walsh MA, Hughes PM. MRI appearance of muscle denervation. Skeletal Radiol. 2008;37: 397-404.

24. Holl N, Echaniz-Laguna A, Bierry G, et al. Diffusion-weighted MRI of denervated muscle; a clinical and experimental study. Skeletal Radiol. 2008;37:1111-17.

25. Bendszus M, Koltzenburg M, Wessig C, Solymosi L. Sequential MR imaging of denervated muscle: experimental study. Am J Neuroradiol. 2002;23:1427-31.

26. Ginsberg L, Malik O, Kenton AR, et al. Coexistent hereditary and inflammatory neuropathy. Brain. 2004;127:193-202. 